\title{
Awareness and utilisation of quitline among current tobacco users in a district in southern india
}

\author{
Somya Mullapudi ${ }^{1}$, Veena G Kamath ${ }^{2}$, Muralidhar M Kulkarni ${ }^{3}$, Asha Kamath ${ }^{4}$, Rohith Bhagawath ${ }^{5}$, \\ Radhika Nayak ${ }^{6}$
}

${ }^{1}$ Research Fellow, Department of Community Medicine, Kasturba Medical College (KMC), Manipal Academy of Higher Education (MAHE), Manipal, India; ${ }^{2}$ Professor, Department of Community Medicine, Kasturba Medical College (KMC), Manipal Academy of Higher Education (MAHE), Manipal, India, ${ }^{3}$ Associate Professor, Department of Community Medicine, Kasturba Medical College (KMC), Manipal Academy of Higher Education (MAHE), Manipal, India; ${ }^{4}$ Professor \& Head, Department of Data Science, Prasanna School of Public Health (PSPH), Manipal Academy of Higher Education (MAHE), Manipal, India; ${ }^{5}$ Social Scientist, Department of Community Medicine, Kasturba Medical College (KMC), Manipal Academy of Higher Education (MAHE), Manipal, India; ${ }^{6}$ Research Fellow, Department of Community Medicine, Kasturba Medical College (KMC), Manipal Academy of Higher Education (MAHE), Manipal, India

\begin{tabular}{|c|c|c|c|c|c|c|c|c|}
\hline Abstract & Introduction & Methodology & Results & Conclusion & References & Citation & \multicolumn{2}{|c|}{ Tables / Figures } \\
\hline \multicolumn{9}{|c|}{ Corresponding Author } \\
\hline \multicolumn{8}{|c|}{$\begin{array}{l}\text { Dr. Veena G Kamath, Professor, Department of Community Medicine, Kasturba Medical college, } \\
\text { Manipal Academy of Higher Education, Manipal-576104. } \\
\text { E Mail ID: veenak@manipal.edu }\end{array}$} & 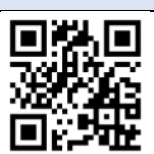 \\
\hline
\end{tabular}

\section{Citation}

Mullapudi S, Kamath VG, Kulkarni MM, Kamath A, Bhagawath R, Nayak R. Awareness and utilisation of quitline among current tobacco users in a district in southern india. Indian J Comm Health. 2021;33(1):175-181. https://doi.org/10.47203/IJCH.2021.v33i01.024

Source of Funding: Nil Conflict of Interest: None declared

\section{Article Cycle}

Received: 28/11/2020; Revision: 18/01/2021; Accepted: 27/02/2021; Published: 31/03/2021

This work is licensed under a Creative Commons Attribution 4.0 International License.

\section{Abstract}

Background: Tobacco use not only increases mortality, but also causes enormous burden to the Nation's health and economy. The WHO -Framework Convention on Tobacco Control implemented "MPOWER", comprising of an important entity of 'offering help to tobacco users' to quit. Quitline provides evidence-based treatment services to tobacco users and advertising those services has the potential to increase their utilisation. Objectives: Our objective was to assess the awareness and utilisation of the newly introduced quitline on tobacco packs among tobacco users. Materials and Methods: After obtaining Ethics Committee approval, this cross-sectional study was conducted from March-June 2019 in a purposive sample of tobacco users aged 18 years and above at the point of sale with prior informed consent. The questionnaire included questions on the users' knowledge and utilisation of the quitline. Results: Most of the tobacco users (84.6\%) had not observed the quitline on tobacco pack. Amongst those who observed the quitline, $65.5 \%$ were smokers, while the smokeless tobacco users who comprised half of the study population were unaware of the quitline. More than $97 \%$ of illiterates were unaware of the quitline. Only three tobacco users who were aware of quitline had tried using it. Conclusion: Most of the tobacco users had basic education but were not aware of the quitline on the tobacco packs and only a very few of them used the services, highlighting the need to increase its awareness for effective tobacco control.

\section{Keywords}

Tobacco Users; Quitline; Awareness; Utilisation 


\section{Introduction}

Tobacco use has been causing enormous burden to the Nation's health and economy with more than 266 million adults above the age of 15 years using tobacco in any form,(1) underscoring the importance of measures to be taken for quitting. Quitting has both periodic and long standing advantages on the wellbeing of an individual.(2) It however seems challenging due to nicotine addiction, which is also responsible for high relapse rates.(2)

As per the GATS II survey report, one in ten adults use smoke form of tobacco while one in five use the smokeless form with one-third of them making an attempt to quit their tobacco habit. There lies a responsibility on the Government to provide congenial anti-tobacco policies to reduce prevalence of tobacco use.(2) In India, there have been periodical introduction of new policies in an attempt to reduce tobacco burden as recommended by the "MPOWER" principles of WHO -Framework Convention on Tobacco Control.(3) The quitline service 1800-11-2356 was introduced from September 1st 2018 and printing on every tobacco pack along with the text warning was made mandatory.$(4,5)$ The National Tobacco Quitline Service (NTQLS) was launched by the Government of India on the World No Tobacco Day. These services assist tobacco users with a toll free call from the number 1800-11-2356 followed by four calls through the same number to create an individualised plan for quitting like creating a quit date and adjusting to the users' needs and also helps in clarifying their questions.(6) According to the World Health Organization, a similar help line has been under use in more than 50 countries across the globe, out of which only 17 of them are low-middle income countries.(7) These helplines are available at low cost, have potential for high reach, and can be tailored individually and are maintained by the National Institute of Mental Health and Neurosciences. $(8,9)$ Smokers using quitline are twice likely to quit compared to non-users, and those using these services with adjuvant pharmacotherapy are thrice likely to quit.(2)

It has been over two years since the introduction of quitline in India, and there is paucity of information about its awareness and utilisation (10).

\section{Aims \& Objectives}

To assess the awareness and utilisation of quitline among tobacco users and to further explore the opinion of current tobacco users on recently introduced quitline services.

\section{Material \& Methods}

This cross-sectional study has been carried out from March-June 2019 after obtaining approval from the Institutional ethics committee (Ref no. IEC153-2019). The petty shops, general shops, grocery stores selling tobacco distributed across the seven taluks of Udupi district were selected by convenience sampling.

The talukas included Udupi, Karkala, Kundapura, Bramhavara, Byndoor, Kaup and Hebri. At each points of sale (PoS), 3-4 tobacco users selected by purposive sampling were interviewed using a semistructured questionnaire after obtaining a written informed consent. About 15 PoS were covered in each taluka with a total of 105 PoS in the district. The questionnaire gathered information regarding their education, occupation, duration of tobacco use, along with knowledge and utilisation of the quitline. The questionnaire consisted of about 20 questions which took approximately 15 minutes to complete. Sample Size: Considering the awareness regarding quitline as $25 \%$ (as per the pilot study conducted in the same region) with $95 \%$ confidence level and an absolute precision of $5 \%$ accounting for $20 \%$ nonresponse, a minimum of 330 tobacco users were needed to be interviewed.

Analysis: The data were entered in the Kobo Toolbox application and exported to excel V16.0. Further statistical analysis was done using the descriptive statistics on SPSS version 15.0. The data have been presented as frequency and percentages for sociodemographic variables and awareness and utilisation of quitline. Chi-square test has been performed to understand the variation in awareness and utilisation of quitline among the tobacco user groups. The variables were recategorized and multivariate regression analysis was performed.

\section{Results}

A total of 356 tobacco users were approached and enrolled for the study. The mean age of the users was 41.9 years $(S D=13.8)$. Majority $(88.5 \%)$ of the users were literate, with fifty percent of them either skilled or semi-skilled workers, and the other half comprised of the unskilled, homemakers, students and those not working. The median duration of tobacco use was 12 years $(I Q R=50)$. Only one third of the respondents (34.7\%) used tobacco for more than 15 years. Almost half of the tobacco users used smokeless form of tobacco (48.9\%), followed by 
smoke form and lastly the dual users, who used both

the smoke form and smokeless form of tobacco. All these details are shown in (Table 1).

Awareness of quitline: Most of the tobacco users $(84.6 \%)$ had not observed any quitline on tobacco packs. About $97.5 \%$ of the illiterates were unaware of the quitline. Twenty eight out of 356 tobacco users thought there should be awareness programs or advertisements on quitline as depicted in (Table 1 ). About $23(41.8 \%)$ out of 55 tobacco users who had seen the quitline on tobacco packs perceived that it was helpful to quit tobacco, while only seven felt it would help prevent uptake. More than $50 \%$ of those who were aware of the quitline belonged to the age group 31-50 years.

On univariate analysis, people using smoked form of tobacco, tobacco users aged $<30$ years, graduates and above and those with lesser number of years of tobacco use were significantly associated with awareness of quitline at a $p$ value of $<0.001$ (Table 2). Subsequently a multivariate logistic regression model was performed where $>30$ years was associated with higher odds of awareness of quitline ( $\mathrm{OR}=0.3,95 \% \mathrm{Cl}=0.1,0.6)$; educated at and above preuniversity was associated with 2.7 times higher odds $(\mathrm{Cl}=1.2,6.2)$; not working at 3.5 times higher odds $(\mathrm{Cl}=1,12.5)$; 15 years of tobacco use had 2.4 times higher odds $(\mathrm{Cl}=1,7.1)$ and Smokeform of tobacco use associated with 6.4 times higher odds $(\mathrm{Cl}=2.5,16.1)$ of awareness of quitline. (Table 3 )

Utilisation of quitline: Out of the 55 smokers who were aware of the quitline, only three $(5.5 \%)$ had utilised the services, implying utilisation was significantly less among those who were aware. Out of the three who used quitline, two users remembered the number. All the three users were educated, of less than 30 years of age and had been using tobacco for upto seven years, but continued to use tobacco after the call. However, none of them knew about the timings to call and one among them had difficulty in connecting to it, while all three of them were unsure regarding its utility. None of them were able to say if they were satisfied with the counsellor's suggestions over phone.

The therapy suggested to the participants were telephonic counselling support, nicotine replacement therapy and other related advice. The quitline counsellor called back two of the three tobacco users for follow up. Among the 55 tobacco users who were aware of the quitline, $6.5 \%$ thought the quitline services were useful for quitting tobacco.

\section{Discussion}

Our study demonstrates very low awareness of quitline among the tobacco users even after two years of its introduction, more so among less educated, smokeless tobacco users, longer duration of use and people more than 50 years of age. It was observed that smokers at and below 30 years and non-working group (Home maker, students and unemployed) were more aware of quitline. On multivariate regression analysis, it was also observed that inclusion of an interaction of age and occupation in the model identified a significance in interaction as most non-workers group above 30 years were less aware of quitline, the possible confounding factors in our study. Our study additionally hints at poor service utilisation among those who were aware of the quitline.

Quitline is relatively new in our nation and needs to be evaluated and ours is the first known study to the best of our knowledge, in the country on the awareness and utilisation of the National quitline. Our findings suggest smoke form of tobacco users less than 30 years and graduates were significantly associated with awareness of quitline. Our study findings are similar to that of a study done in U.S. by Kaufman et al (11) wherein less than 35 years were more aware of quitline than 65 and above age group. Our results present with more than three-fourths of tobacco users not being aware of the presence of quitline. This could be attributed to its recent introduction by the Government and also the unrestrained sale of loose cigarettes (95\%) (12) that prevents the smoker from looking at the packs. Although quit line on tobacco packs has been introduced recently in India, a study in 2013 on voluntary local reactive helpline initiated for Tobacco cessation in Rajasthan showed a low awareness among the study population,(13) possibly due to dismal Information, Education and Communication (IEC). This is in contrast to a study by Fehily in 2017(14) in an Australian community mental health service, wherein a high awareness (89\%) and utilisation (18\%) of quitline was observed, probably due to the active media campaigns after the introduction of quitline way back in 1997. However, a multivariable logistic regression revealed that no factors were significantly associated with awareness of quitline.

Quitline is an important entity of the text health warning and past studies emphasize the need to 
strengthen health warnings to augment quitline utilisation.(15) In our study, the awareness of quitline in smokers was found to be better compared to the smokeless form of tobacco users. SLT users tend to be more among lower economic strata and are likely to benefit if the information reaches to them and are able to quit the habit. This calls for a systematic approach to impart awareness across all sections of society so that every tobacco user knows about the quitline service.

Previous literature points that the awareness and utilisation of quitline in developing countries was low, $(11,16)$ but it has been seen that with a range of ancillary measures in place, the utilisation of quitline can be increased. One such measure of an increase in tax on cigarettes along with anti-tobacco propaganda on media increased the utilisation of quitline and website services.(17) Another measure of reinforcing the anti-smoking laws showed improved quitline utilisation. $(18,19)$

Health warnings are a cost-effective mode of tobacco control and it is known that larger the warnings, better is their impact. The combination of quitline and health warning may augment their awareness and utilisation, as each of them seem to be dependent on one another. For instance, as per a study in New South Wales and Australian Capital Territory, post graphical health warnings in 2006 there was an increase in quit calls by $84 \%$ and post introduction of Plain packaging there was an instant sustained increase in quit calls by $78 \%$. (20)

Additional affordable modalities such as mass communication are known to increase the utilisation of quitline especially in LMICs and past studies on quitline utilisation through awareness created by vigorous educational (21) and media campaigns via television, print and radio, (22) provides evidence to its increased utilisation especially on a short term followed by moderate intermediate results necessitating further research.

\section{Conclusion}

Despite basic education, most of the tobacco users were unaware of the quitline on the tobacco packs. Majority of tobacco users who were aware of the quitline were smoke form of tobacco users, implying a poor awareness in the other two groups namely dual and smokeless tobacco (SLT) users. Presently, the predominance of SLT users among tobacco users' mandates that quitline is not just important for smoked forms of tobacco but also SLT users.

\section{Recommendation}

Since quitlines have been shown to be evidencebased and effective, it is crucial to make tobacco users aware that the quitline exists by effective promotion (which might include mass media). Also, highlighting that quitline is available at no cost to them would eventually increase its utilisation. The integration of mCessation' Programme in the form of text messaging along with quitline services could aid in follow-up and providing continued support to users willing to quit tobacco (2)

\section{Limitation of the study}

Our study has a limitation of self-reporting bias from the purposive sample chosen

\section{Relevance of the study}

Our study is imperative in the present scenario since quitlines provide treatment services to tobacco users and advertising them and thereby promoting those services has the potential to increase quit line utilisation, which is one of the cost effective means of tobacco control.

\section{Authors Contribution}

VK and MK conceptualised the work and the manuscript was drafted by $\mathrm{SM}, \mathrm{RB}, \mathrm{RN}$; critically revised by VK, AK and MK. Data collection activity was coordinated by SM and RB. Data analysis and interpretation was carried out by SM, RB, VK, AK and $M K$ and all authors equally contributed to the final approval of the manuscript. Agreement to be accountable for all aspects of the work in ensuring that questions related to the accuracy or integrity of any part of the work are appropriately investigated and resolved.

\section{Acknowledgement}

We would like to thank the District Tobacco Control Cell (DTCC) for their financial support in carrying out the study and Social Workers of the Department of Community Medicine, KMC, Manipal for their meticulous data collection. Authors are also thankful to the Tobacco Control Capacity Programme (MR/P027946/2) for providing leads to carry out research in applied aspects for tobacco control.

\section{References}

1. Ministry of Health and Family Welfare. TOBACCO SURVEY INDIA 2016-2017 | RepoRt. 2017. Available from: https://www.who.int/tobacco/surveillance/survey/gats/G ATS India 2016-17 FactSheet.pdf 
INDIAN JOURNAL OF COMMUNITY HEALTH / VOL 33 / ISSUE NO 01 / JAN- MAR 2021

2. Vijayarani M, Balamurugan G, Nagarajaiah. Tobacco cessation: An Indian perspective. Indian J Psychiatr Nurs. 2015;9(1):42-5.

3. Operational Guidelines National Tobacco Control Programme National. National Tobacco Control Cell Ministry of Health and Family Welfare Government of India. 2012.

4. Heydari G. A decade after introducing MPOWER, trend analysis of implementation of the WHO FCTC in the Eastern Mediterranean Region. Lung India. 2020 Mar-;37(2):120125. doi: 10.4103/lungindia.lungindia_388_19. PMID: 32108595; PMCID: PMC7065548. [PubMed].

5. 'Quit Line' Number on all Tobacco Products. Available from: https://www.onlymyhealth.com/quit-line-number-on-alltobacco-products-from-september-1534922309 [cited 2021 Feb 22]

6. Kumar R, Jha AK, Munish VG, Pusp A, Sinha P, Gupta P, et al. National Tobacco Quitline: the preliminary Indian experience. Indian J Chest Dis Allied Sci. 2018;60(1):7-12.

7. Worldwide current situation of national quit-line services. Developing and improving national toll-free tobacco quitline services. p. 12-4. Available from: https://www.who.int/tobacco/publications/smoking cess ation/worldwide current situation who tobacco quit lin e.pdf?ua=1 [cited $2021 \mathrm{Feb} 22$ ]

8. Greenhalgh, EM., Stillman, S., \& Ford C. Cessation assistance: telephone- and internet-based interventions. Tobacco in Australia: Facts and issues. 2020. Available from: https://www.tobaccoinaustralia.org.au/chapter-7cessation/7-14-methods-services-and-products-forquitting-te\#x2 [cited 2021 Feb 22]

9. Narasimha GVL, Pratima Murthy. Preventing Tobacco Use among Young People. J Sustain Heal India. 2019;1:1-5.

10. Bhatt $\mathrm{G}$, Goel S. Using non-communicable disease clinics for tobacco cessation: A promising perspective. Natl Med J India. 2018 May- Jun;31(3):172-175. doi: 10.4103/0970258X.255763. PMID: 31044768.[PubMed]

11. Kaufman A, Augustson E, Davis K, Finney Rutten LJ. Awareness and use of tobacco quitlines: evidence from the Health Information National Trends Survey. J Health Commun. 2010;15 Suppl 3(0 3):264-78. doi: 10.1080/10810730.2010.526172. PMID: 21154098; PMCID: PMC3755755.[PubMed]

12. Eshwari K, Kulkarni MM, Bhagawath R, Mullapudi S, Selvarajan T, Kamath VG. Ban on sale of loose cigarettes: Awareness, perceptions and practices among vendors and smokers in Karnataka, India. Indian J Community Heal. 2020;32(2):394-8.

13. Gupta R, Verma V, Mathur P. Quitline Activity in Rajasthan, India. Asian Pac J Cancer Prev. 2016;17(S2):19-24. doi: 10.7314/apjcp.2016.17.s2.19. PMID: 27108749.[PubMed]
[Current tobacco users] | Mullapudi S et al

14. Fehily C, Latter J, Bartlem K, Wiggers J, Bradley T, Rissel C, Reakes K, Reid K, Browning E, Bowman J. Awareness and use of telephone-based behaviour change support services among clients of a community mental health service. Aust N Z J Public Health. 2020;44(6):482-488. doi: 10.1111/17536405.13039. Epub 2020 Oct 26. PMID: 33104282.[PubMed]

15. Noar SM, Francis DB, Bridges C, Sontag JM, Brewer NT, Ribisl KM. Effects of Strengthening Cigarette Pack Warnings on Attention and Message Processing: A Systematic Review. Journal Mass Commun Q. 2017;94(2):416-442. doi: 10.1177/1077699016674188. Epub 2016 Oct 28. PMID: 29975497; PMCID: PMC5483339.[PubMed]

16. Schauer GL, Malarcher AM, Zhang L, Engstrom MC, Zhu SH. Prevalence and correlates of quitline awareness and utilization in the United States: an update from the 20092010 National Adult Tobacco Survey. Nicotine Tob Res. 2014;16(5):544-53. doi: 10.1093/ntr/ntt181. Epub 2013 Nov 19. PMID: 24253378. [PubMed]

17. Keller PA, Greenseid LO, Christenson M, Boyle RG, Schillo BA. Seizing an opportunity: increasing use of cessation services following a tobacco tax increase. BMC Public Health. 2015;15:354. doi: 10.1186/s12889-015-1667-8. PMID: 25880373; PMCID: PMC4411932.[PubMed]

18. Chan SS, Leung DY, Leung AY, Lam DO, Fong DY, Lam TH. New anti-smoking legislation on youth smoking and quitting behaviours via a smoking cessation hotline. Hong Kong Med J. 2011;17(3 Suppl 3):43-6. PMID: 21673360.[PubMed]

19. Edwards R, Thomson G, Wilson N, Waa A, Bullen C, O'Dea D, Gifford H, Glover M, Laugesen M, Woodward A. After the smoke has cleared: evaluation of the impact of a new national smoke-free law in New Zealand. Tob Control. 2008;17(1):e2. doi: 10.1136/tc.2007.020347. PMID: 18218788. [PubMed]

20. Young JM, Stacey I, Dobbins TA, Dunlop S, Dessaix AL, Currow DC. Association between tobacco plain packaging and Quitline calls: a population-based, interrupted timeseries analysis. Med J Aust. 2014;200(1):29-32. doi: 10.5694/mja13.11070. PMID: 24438415.[PubMed]

21. Zhang L, Vickerman $K$, Malarcher A, Mowery $P$. Intermediate cessation outcomes among quitline callers during a national tobacco education campaign. Nicotine Tob Res. 2014;16(11):1478-86. doi: 10.1093/ntr/ntu105. Epub 2014 Jul 8. PMID: 25006045.[PubMed]

22. Farrelly MC, Hussin A, Bauer UE. Effectiveness and cost effectiveness of television, radio and print advertisements in promoting the New York smokers' quitline. Tob Control. 2007;16 Suppl 1(Suppl 1):i21-3. doi: 10.1136/tc.2007.019984. PMID: 18048625; PMCID: PMC2598515. [PubMed]. 


\section{Tables}

TABLE 1 EDUCATION, TOBACCO USE AND QUITLINE AWARENESS AMONG TOBACCO USERS ( $\mathbf{N}=356$ )

\begin{tabular}{|c|c|c|}
\hline \multirow{2}{*}{\multicolumn{3}{|c|}{ Age }} \\
\hline & & \\
\hline$<30$ & 84 & 23.6 \\
\hline $31-50$ & 182 & 51.1 \\
\hline$>50$ & 90 & 25.3 \\
\hline \multicolumn{3}{|l|}{ Education status } \\
\hline Illiterate & 41 & 11.5 \\
\hline Primary (1-7 std) and can read & 170 & 47.8 \\
\hline High School (8-10 std) and Pre-university & 118 & 33.1 \\
\hline Graduate and above & 27 & 7.6 \\
\hline \multicolumn{3}{|l|}{ Occupation } \\
\hline Skilled & 77 & 21.6 \\
\hline Semi-skilled & 125 & 35.1 \\
\hline Unskilled & 124 & 34.9 \\
\hline Home maker & 6 & 1.7 \\
\hline Student & 14 & 3.9 \\
\hline Not working & 10 & 2.8 \\
\hline \multicolumn{3}{|l|}{ Years of tobacco use: } \\
\hline$<10$ years & 165 & 46.9 \\
\hline $11-20$ years & 99 & 28.1 \\
\hline$>20$ years & 88 & 25.0 \\
\hline \multicolumn{3}{|l|}{ Form of Tobacco Product used } \\
\hline Smoke & 107 & 30.1 \\
\hline Smokeless & 174 & 48.8 \\
\hline Both Smoke and Smokeless & 75 & 21.1 \\
\hline \multicolumn{3}{|c|}{ Perception that awareness programs and advertisements are needed to increase utilization } \\
\hline Yes & 28 & 7.9 \\
\hline No & 62 & 17.4 \\
\hline Not sure & 198 & 55.6 \\
\hline No response & 68 & 19.1 \\
\hline \multicolumn{3}{|c|}{ Observed any number below the Health warning on a tobacco pack } \\
\hline Yes & 55 & 15.4 \\
\hline No & 301 & 84.6 \\
\hline
\end{tabular}

TABLE 2 FACTORS ASSOCIATED WITH AWARENESS ABOUT QUITLINE AMONG PARTICIPANTS

\begin{tabular}{|c|c|c|c|}
\hline Factor & Category & Aware N (\%) & Not-aware N (\%) \\
\hline \multirow{3}{*}{ Age } & $<30$ years & 34 (40.5\%) & 50 (59.5\%) \\
\hline & $31-50$ Years & 21 (11.5\%) & 161 (88.5\%) \\
\hline & $>50$ years & $0(0)$ & $90(100 \%)$ \\
\hline \multirow[t]{4}{*}{ Education } & Illiterate & $1(2.5 \%)$ & $39(97.5 \%)$ \\
\hline & Primary & $10(5.9 \%)$ & $160(94.1 \%)$ \\
\hline & High school and Pre-University & 19 (16.1\%) & 99 (83.9\%) \\
\hline & Graduate and above & $25(87.5 \%)$ & $2(12.5 \%)$ \\
\hline \multirow[t]{6}{*}{ Occupation status } & Unskilled & $9(7.3 \%)$ & $115(92.7 \%)$ \\
\hline & Semi-skilled & $13(10.4 \%)$ & $112(89.6 \%)$ \\
\hline & Skilled & $21(27.3 \%)$ & $56(72.7 \%)$ \\
\hline & Home maker & $0(0 \%)$ & $6(100 \%)$ \\
\hline & Student & $12(85.7 \%)$ & 2 (14.3\%) \\
\hline & Not working & $0(0)$ & $10(100 \%)$ \\
\hline \multirow{2}{*}{ Years since tobacco use } & $<10$ years & $40(24.2 \%)$ & 125 (75.8\%) \\
\hline & $11-20$ years & $13(13.1 \%)$ & $86(86.9 \%)$ \\
\hline
\end{tabular}




\begin{tabular}{|l|l|l|l|}
\hline \multirow{2}{*}{ Type of Tobacco user } & $>20$ years & $1(1.1 \%)$ & $87(98.9 \%)$ \\
\hline & Smoke form & $36(33.6 \%)$ & $71(66.4 \%)$ \\
\cline { 2 - 4 } & Smokeless form & $7(4.0 \%)$ & $167(96.0 \%)$ \\
\cline { 2 - 4 } & Both Smoke and Smokeless form & $12(16.0 \%)$ & $63(84.0 \%)$ \\
\hline
\end{tabular}

\section{TABLE 3 AWARENESS OF QUITLINE AMONG TOBACCO USERS}

\begin{tabular}{|c|c|c|c|c|c|c|c|}
\hline Variables & $\mathbf{N}$ & $\begin{array}{l}\text { Aware } \\
(1.00)\end{array}$ & Not Aware & $\begin{array}{l}\text { Univariate } \\
\text { OR }(95 \% \mathrm{CI})\end{array}$ & $\begin{array}{c}\mathrm{P}- \\
\text { value }\end{array}$ & $\begin{array}{l}\text { Adjusted OR } \\
\text { (95\% CI) }\end{array}$ & $\begin{array}{c}P \text { - } \\
\text { value }\end{array}$ \\
\hline Age: & & & & & $<0.001$ & & 0.002 \\
\hline$\leq 30$ & 84 & $34(40.5)$ & $50(59.5)$ & 1 & & 1 & \\
\hline$>30$ & 272 & $21(7.7)$ & $251(92.3)$ & $0.1(0.1,0.2)$ & & $0.3(0.1,0.6)$ & \\
\hline Education: & & & & & $<0.001$ & & 0.015 \\
\hline Illiterate/Primary & 211 & $11(5.2)$ & $200(94.8)$ & 1 & & 1 & \\
\hline $\begin{array}{l}\text { Preuniversity/Graduate and } \\
\text { above }\end{array}$ & 145 & $44(30.3)$ & $101(69.7)$ & $7.9(3.9,16.0)$ & & $2.7(1.2,6.2)$ & \\
\hline Occupation & & & & & $<0.001$ & & 0.057 \\
\hline Unskilled/semiskilled/skilled & 326 & $43(13.2)$ & $283(86.8)$ & 1 & & 1 & \\
\hline $\begin{array}{l}\text { Home maker/student/not } \\
\text { working }\end{array}$ & 30 & $12(40.0)$ & $18(60.0)$ & $4.4(2.0,9.7)$ & & $3.5(1.0,12.5)$ & \\
\hline Years since tobacco use & & & & & $<0.001$ & & 0.115 \\
\hline$>15$ & 122 & $5(4.1)$ & $117(95.9)$ & 1 & & 1 & \\
\hline$\leq 15$ & 230 & $49(21.3)$ & 181 (78.7) & $6.3(2.5,16.4)$ & & $2.4(1.0,7.1)$ & \\
\hline Type of Tobacco Product & & & & & $<0.001$ & & $<0.001$ \\
\hline Smokeless form & 174 & $7(4.0)$ & $167(96.0)$ & 1 & & 1 & \\
\hline Smokeform+smokeless form & 75 & $12(16.0)$ & $63(84.0)$ & $4.5(1.7,12.1)$ & 0.002 & $4.9(1.8,13.9)$ & 0.002 \\
\hline Smoke form & 107 & $36(33.6)$ & $71(66.4)$ & $\begin{array}{l}12.1(5.1 \\
28.8)\end{array}$ & $<0.001$ & $6.4(2.5,16.1)$ & $<0.001$ \\
\hline
\end{tabular}

